\title{
Life beyond the Summit
}

\author{
The UN Food Systems Summit brought together a breadth of civil society, scientists, industry and policymakers. \\ Its legacy requires ongoing efforts for innovation, inclusivity and trust, and accountability to ensure high-level \\ commitments are honoured.
}

$\mathrm{T}$ he Nature Food readership knows well that global food systems need a radical overhaul. Growing are the numbers of hungry and malnourished people in the world, and growing is the distance between the targets of and progress on the UN Sustainable Development Goal 2 , achieving zero hunger. The actors and actions of food systems are responsible for about a third of greenhouse gas emissions, destruction of natural resources and entrenchment of multiple forms of human poverty. The UN Food Systems Summit (UNFSS), held on 23 September, has offered a historic opportunity to draw global attention to these failings, and to begin the process of reparative change.

Special Envoy to the UNFSS, Agnes Kalibata, emphasized the criticality of science and policy working hand-in-glove to effect that change, quickly (Nat. Food $2,313-314 ; 2021)$, and the architecture of the UNFSS, with the prominence of a scientific group alongside political actors, was designed to facilitate these factions. Five tasks were identified to keep action on-track for all participants towards the 2030 Sustainable Development Goal agenda: ensure access to safe and nutritious foods for all, shift towards sustainable consumption patterns, boost nature-positive agriculture, advance equitable livelihoods, and build resilience to vulnerabilities, shocks and stress. To ensure common understanding and concerted action at the science-policy interface, concepts and definitions of food systems were foundational to the work of the UNFSS, as presented in this issue of Nature Food in a Comment by Joachim von Braun and colleagues.

Dubbed 'The People's Summit', the UNFSS aimed to be inclusive, with special focus on de-marginalizing women, Indigenous People and youth from decision-making. Groups representing
Indigenous People called for the complete and persistent integration of traditional knowledge into processes of evidence consideration and policymaking; that the food systems science-policy interface works hand-in-glove with Indigenous Peoples' and traditional knowledge systems.

In this issue, a Correspondence from Joanna Trewern and colleagues describes the engagement of over 10,000 young people in the UNFSS, and the priorities of youth elicited through the consultative processes. The number one priority of youth emerged as shifts in consumption patterns, for all, towards healthy and sustainable diets. Implicit in their demand is the definition and communication of, and shaping of food environments towards, what is healthy and what is sustainable. While the conceptualization of healthy and sustainable dietary patterns is emerging, through for example the EAT-Lancet planetary health diet, the characteristics remain somewhat nebulous - and distant - for many consumers. Better tools are needed for common understanding and concerted action towards healthy, sustainable consumption patterns.

One such tool for informing decisions on the healthfulness of foods are nutrient profiling systems, such as the Food Compass presented in an Article by Dariush Mozaffarian and colleagues. An expansive set of attributes - including food processing and the presence and amount of nutrients and non-nutrients can be combined to convey a streamlined understanding of the healthfulness of foods. Nutrient profiling systems can be used at multiple levels in food systems, such as in setting food standards, determining marketing restrictions, motivating industry reformulations and informing consumers with front-of-package labelling.
Defining and communicating sustainable diets, and shaping food environments towards sustainable behaviour, also has challenges. Global market share of sustainability-certified products remains small, and consumer food choices are influenced more by price, product appearance, nutrition and taste than sustainability, according to a Review Article by Eva-Marie Meemken and colleagues in this issue. Communicating what a sustainable diet for consumers is relies to some extent on attribute credence and trust, and so, without systems of scientifically profiling the climate and environmental impacts of food choices, the potential for greenwashing is huge.

In the wake of the UNFSS, solution clusters and coalitions have formed and the work ahead is great. Technical solutions for transformation must be delivered with equity and justice, inclusive of people and knowledge systems, and tailored to empower consumers to make healthy, sustainable food choices. A people-centred focus to what we, the food science community, do is critical. But, key to the legacy of the UNFSS are the commitments made in September to food systems by the powerful from politics and industry. Many will voice commitments again this year at the 26th Conference of the Parties (COP26) to the UN Framework Convention on Climate Change. It is imperative that we do not allow the food crisis to be separated from the climate crisis. In life beyond the Summit, the food community must hold the powerful to account to ensure that political commitments made for food systems are hand-in-glove with commitments made for climate.

Published online: 19 October 2021 https://doi.org/10.1038/s43016-021-00401-x 